\title{
Localization of the IGF binding domain and evaluation of the role of cysteine residues in IGF binding in IGF binding protein-4
}

\author{
D Byun ${ }^{1,2}$, S Mohan ${ }^{1,2,3,4}$, D J Baylink ${ }^{1,2,3}$ and X Qin ${ }^{1,2}$ \\ ${ }^{1}$ Musculoskeletal Disease Center, J L Pettis Memorial Veterans' Medical Centre, Loma Linda, California 92357, USA \\ ${ }^{2}$ Department of Medicine, Loma Linda University, Loma Linda, California 92357, USA \\ ${ }^{3}$ Department of Biochemistry, Loma Linda University, Loma Linda, California 92357, USA \\ ${ }^{4}$ Department of Physiology, Loma Linda University, Loma Linda, California 92357, USA \\ (Requests for offprints should be addressed to X Qin, Musculoskeletal Disease Center, J L Pettis VA Medical Center (151), 11201 Benton Street, \\ Loma Linda, California 92357, USA; Email: Xuezhong.Qin@med.va.gov)
}

\begin{abstract}
Our previous findings suggest that binding of IGF binding protein-4 (IGFBP-4) to IGFs is essential for the inhibitory effect of IGFBP-4 on the activity of IGFs, both in vitro and in vivo. Therefore, understanding the structural determinants of IGF binding in IGFBP-4 is important to the general understanding of the biology of the IGF system. This study sought to further localize the IGF binding domain and to evaluate the role of Cys residues in IGF binding. Our data revealed that full-length IGFBP-4 peptides lacking the residues $\mathrm{Leu}^{72}-\mathrm{Ser}^{91}$ or $\mathrm{Leu}^{72}-\mathrm{His}^{74}$ or Gly ${ }^{75}-\mathrm{Ser}^{91}$ failed to bind to IGF-I or IGF-II, whereas deletion of the residue $\mathrm{Leu}^{72}$ or residues $\mathrm{Met}^{80}-\mathrm{Ser}^{91}$ led to a 2 - to 3-fold reduction in IGF-I and IGF-II binding activity. The IGF-I and IGF-II binding activities were dramatically reduced by the single mutation, Cys $9 / \operatorname{Arg}$ (>25-fold), and to a lesser degree, by the single mutation, Cys12/Arg (the first N-terminal Cys residue was desig-
\end{abstract}

nated Cys1). The mutation Cys17/Ser or Cys18/Tyr or Cys20/Ser each resulted in a similar but moderate $(\approx 5-$ fold) reduction in IGF-II binding activity. The IGF-I binding activity was also dramatically reduced by the mutation Cys18/Tyr, and to a lesser extent, by the mutation Cys17/Ser or Cys20/Ser. These data suggest: 1) the IGF-I and IGF-II binding domain in IGFBP-4 involves a hydrophobic motif $\left(\mathrm{Leu}^{72}-\mathrm{Met}^{80}\right)$ located in the distal part of the conserved N-terminal region, and 2) the N-terminal Cys residues (Cys9 and Cys12) are more critical than the $\mathrm{C}$-terminal Cys residues (Cys17 and Cys20) in affecting the IGF-I and IGF-II binding. Based on these data, we speculate that the structural determinants of IGF-I and IGF-II binding in IGFBP-4 are very similar, if not identical.

Journal of Endocrinology (2001) 169, 135-143

\section{Introduction}

Insulin-like growth factors (IGFs) are important mediators of physiological growth and metabolism in vivo and promote proliferation and differentiation of a variety of cell types in vitro (Canalis 1993, Rosen et al. 1994, Clemmons 1997, Mohan \& Baylink 1999). The actions of IGFs are either positively or negatively regulated by a family of structurally related IGF binding proteins (IGFBPs) (Canalis 1993, Rosen et al. 1994, Clemmons 1997, Mohan \& Baylink 1999). The mechanisms by which IGFBPs stimulate or inhibit IGF actions have not been clearly defined and may vary among the IGFBPs. In this regard, recent evidence suggests that some of the IGFBPs such as IGFBP-3 may exert IGF independent actions (Valentinis et al. 1995, Mohseni-Zadeh \& Binoux 1997), in addition to modulating IGF actions. Studies in our laboratory demonstrate that IGFBP-4 primarily acts to inhibit cell proliferation by an IGF dependent mechanism (Mohan et al. 1995, Qin et al. 1998, Miyakoshi et al. 1999). Therefore, elucidation of the structural determinants of various IGFBPs in IGF binding is important to the general understanding of the biology of the IGF system and may shed light on how these different IGFBPs exhibit different actions. In this regard, previous deletion analysis revealed that the IGF binding activity of IGFBP-4 is mainly determined by the conserved residues in the $\mathrm{N}$-terminal region, and to a lesser extent, by the residues in the conserved C-terminal region (Qin et al. 1998). Although the three-dimensional structure of any intact IGFBPs has not been determined, disulfide bridging in IGFBPs appears to be important for maintaining the secondary structures required for IGF binding, since all six IGFBPs contain conserved Cys residues in both the N-terminal and the C-terminal regions and reduced IGFBPs exhibit little or no IGF binding activity (Landale et al. 1995, Qin et al. 1998, Neumann \& Bach 1999). Except for that in IGFBP-6, the disulfide linkage in other IGFBPs has only 
Table 1 Sequences of the PCR primers used for preparation of IGFBP-4 analog expression constructs

\section{Primer sequences}

\section{Mutants}

$\Delta \mathrm{Leu}^{72}$

$\Delta \mathrm{Leu}^{72}-\mathrm{His}^{74}$

$\Delta l \mathrm{e}^{80}-\mathrm{Ser}^{91}$

$\Delta$ Gly $^{75}-$ Ser $^{91}$

$\Delta$ Leu $^{72}-$ Ser $^{91}$

Cys9/Arg

Cys12/Arg

Cys17/Ser

Cys18/Tyr

Cys20/Ser
Forward TGT GTG CAG GGG CTT CTC CAC CCC Reverse ATG CAC GGG CAA GGC GTG TGC ATG Forward TGT GTG CAG GGG CTT CTC CAC CCC Reverse GGG CAA GGC GTG TGC ATG GAG CTG Forward GCA CAC GCC TTG CCC GTG CAT CAG Reverse CTG CAG CCC TCT GAC AAG GAC GAG Forward GTG CAT CAG TGT GTG CAG GGG CTT Reverse CTG CAG CCC TCT GAC AAG GAC GAG Forward TGT GTG CAG GGG CTT CTC CAC CCC Reverse CTG CAG CCC TCT GAC AAG GAC GAG

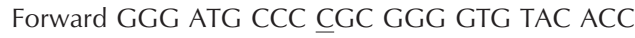
Reverse GGT GTA CAC CCC GCG GGG CAT CCC Forward GGG CAA GGC GTG CGC ATG GAG CTG Reverse CAG CTC CAT GCG CAC GCC TTG CCC Forward CCC AAG CAG AGT CAC CCA GCT CTG Reverse CAG AGC TGG GTG ACT CTG CTT GGG Forward CGT GGC AAG TAC TGG TGT GTG GAC Reverse GTC CAC ATA CCA GTA CTT GCC ACG Forward GGG GAG CTG GAC TCC CAC CAG CTG Reverse CAG CTG GTG GGA GTC CAG CTC CCC
New restriction site created $^{1}$
Sacll
Fspl
Hinfl
Scal
Hinfl

${ }^{1}$ To facilitate screening for desired mutations, primers were designed such that each mutation (underlined nucleotides) would create a new restriction site in the newly synthesized plasmid DNA after PCR.

been partially determined (Hashimoto 1997, Forbes et al. 1998, Kalus et al. 1998, Neumann \& Bach 1999, Standker et al. 2000). These studies demonstrate that some of the disulfide linkages are conserved whereas others may vary among different IGFBPs. Regarding the role of each individual Cys residue or disulfide linkage in IGF binding, the information has been very limited. It has previously been reported that mutation of Cys8 $\left(\mathrm{Cys}^{38}\right)$ in IGFBP-1 led to a loss of IGF binding activity, whereas mutation of Cys6 $\left(\mathrm{Cys}^{34}\right)$ had no effect on IGF binding (Brinkman et al. 1991a). In addition, mutation of the C-terminal Cys18 $\left(\mathrm{Cys}^{226}\right)$ in IGFBP-1 results in dimer formation and loss of IGF binding activity (Brinkman et al. 1991b). The role of Cys residues in IGF binding in other IGFBPs has not been reported. Thus, the purpose of this study is to further localize the IGF binding domain and to evaluate the role of Cys residues in N-terminal and C-terminal domains of IGFBP-4 in determining IGF binding activity.

\section{Materials and Methods}

\section{Materials}

Recombinant human IGF-I and IGF-II peptides were from Bachem, Inc. (Torrance, CA, USA). 125I was from DuPont NEN (Wilmington, DE, USA). Ni-agarose resin and the pQE32 plasmid were from Qiagen (Chatsworth,
CA, USA). The QuikChange Site-Directed Mutagenesis kit and ExSite kit were from Stratagene (La Jolla, CA, USA). XL-blue 1 Eschericia coli competent cells were from Promega (Madison, WI, USA). Reagents for SDS-PAGE were from BIO-RAD (Hercules, CA, USA). All other chemicals used were at least reagent grade and were from Sigma (St Louis, MO, USA).

Preparation of human IGFBP-4 analog constructs with deletion or point mutation

Recombinant 6xHis-tagged wild type IGFBP-4 was prepared as previously described (Qin et al. 1998). This recombinant peptide contained $\mathrm{Gly}^{-5}$ to the carboxyl terminus, Glu ${ }^{237}$ (the first residue Met in the signal peptide was designated -21 ) and was designated 6xHisBP-4(-5/237). The recombinant IGFBP-4 peptides with point mutations and deletions were prepared using the PCR-based QuikChange Site-Directed Mutagenesis kit and ExSite kit respectively. The primers used for PCR are given in Table 1 . The PCR was carried out using the 6 xHis-BP-4(-5/237) plasmid as the template and DNA polymerase, $p f u$, under the following conditions: one cycle of $98^{\circ} \mathrm{C}$ for $3 \mathrm{~min}$ (hot start), 30 cycles each of $98^{\circ} \mathrm{C}$ for $1 \mathrm{~min}$ (denaturation), $65^{\circ} \mathrm{C}$ for $1 \mathrm{~min}$ (annealing), and $72{ }^{\circ} \mathrm{C}$ for $12 \mathrm{~min}$ (extension). The PCR products were treated with $D p n \mathrm{I}$, phosphorylated with alkaline 
phosphatase, self-ligated with T4 DNA ligase, and transformed into E. coli XL blue-1 cells. The desired deletions or mutations were confirmed by DNA sequencing or restriction mapping.

\section{Expression and purification of recombinant IGFBP-4 peptides}

Recombinant IGFBP-4 peptides were expressed in E. coli and purified as previously described (Qin et al. 1998). The peptides, 6 xHis-BP-4( $\Delta 72-74)$ and 6 xHis-BP-4 $(\Delta 75-$ 91), were purified sequentially by $\mathrm{Ni}$-agarose and HPLC reverse phase chromatography. Other recombinant IGFBP-4 peptides were purified sequentially by $\mathrm{Ni}-$ agarose affinity and IGF-I affinity chromatography using procedures described previously (Qin et al. 1998).

\section{Western ${ }^{125}$ I-IGF ligand blot and IGFBP-4 immunoblot analyses}

${ }^{125}$ I-IGF Western ligand blot analysis and IGFBP-4 immunoblot analysis were performed as previously described (Scharla et al. 1991, Honda et al. 1996).

\section{IGFBP-4/IGF-II solution binding assay}

The binding activity of various IGFBP-4 mutants to IGF-II in solution was determined by incubating ${ }^{125} \mathrm{I}-$ IGF-II tracer with IGFBP-4 at various concentrations $(0$ to $500 \mathrm{ng} / \mathrm{ml}$ ) followed by separation of free and bound ${ }^{125}$ I-IGF-II tracer by polyethylene glycol precipitation as previously described (Mohan et al. 1989).

\section{Results}

\section{Localization of the IGF binding domain}

Our previous sequential deletion analysis revealed that residues Leu $^{72}$ to Ser $^{91}$ may represent the IGF binding domain in IGFBP-4 (Qin et al. 1998). To confirm this earlier finding and localize the critical residues for IGF binding in this motif, we prepared several full-length IGFBP-4 peptides with amino acid deletions in this critical region and evaluated their purity by SDS-PAGE under non-reducing (Fig. 1A) or reducing conditions (Fig. 1D). These peptides migrated in SDS-PAGE with anticipated molecular mass. The IGF binding activities of IGFBP-4 analogs were determined by the IGF ligand blotting, followed by densitometric analysis. Deletion of the residues Leu ${ }^{72}$ to $\mathrm{Ser}^{91}$ (data not shown) or Leu ${ }^{72}$ $\mathrm{His}^{74}$ or $\mathrm{Gly}^{75}-\mathrm{Ser}^{91}$ each led to the loss of IGF-I and IGF-II binding activity (Fig. 1B,C). Deletion of the residues $\mathrm{Met}^{80}-\mathrm{Ser}^{91}$ or $\mathrm{Leu}^{72}$ resulted in a slight reduction in IGF-I and IGF-II binding activity (40 to $70 \%$ of the wild type IGFBP-4) (Fig. 1B,C). None of these targeted deletions led to a dramatic preferential effect on IGF-I over IGF-II binding activity.

\section{Evaluation of the role of Cys residues in IGF binding}

To evaluate the role of Cys residues in IGF binding, we first prepared two IGFBP-4 mutants with point mutations at positions of Cys 9 and Cys12 respectively in the $\mathrm{N}$-terminal domain of IGFBP-4. We chose to mutate these two Cys residues because 1) the disulfide linkages Cys9-Cys11 and Cys10-Cys12 appear to be conserved among several IGFBPs (Hashimoto et al. 1997, Neumann \& Bach 1999, summarized in Fig. 2), and 2) these linkages are either within or in close proximity to the established IGF binding domain in IGFBP-4. Under non-reducing conditions, both Cys9/Arg and Cys12/Arg mutant preparations yielded a high molecular weight band in addition to the band of expected masses (Fig. 3A). This high molecular weight band upon reduction with $\beta$-mercaptoethanol was not observed; meanwhile an approximately $38-40 \mathrm{kDa}$ band was revealed (Fig. $3 \mathrm{D}$ ). This $38-40 \mathrm{kDa}$ band was recognized by the IGFBP-4 polyclonal antibody (Fig. 3E) and represented the reduced full-length IGFBP-4 as previously reported (Qin et al. 1998). The Cys $12 /$ Arg mutant preparation also gave a small molecular weight band of approximately $14 \mathrm{kDa}$, which was recognized by the IGFBP-4 antibody (Fig. $3 \mathrm{D}, \mathrm{E})$ and thus represented the IGFBP-4 proteolytic fragment. As determined by the IGF ligand blot analysis, 6xHis-BP-4(Cys9/Arg) exhibited approximately a 25-fold reduction in IGF-I/IGF-II binding activity. The mutation Cys12/Arg also reduced IGF-I and IGF-II binding, but the extent of reduction was less compared with the Cys9/Arg mutation (Fig. 3B,C).

Next, we prepared three IGFBP-4 mutants with point mutations at the positions of Cys17, Cys18, and Cys20 respectively in the $\mathrm{C}$-terminal domain of IGFBP-4. According to a recently published study (Standker et al. 2000), the mutation Cys17/Ser or Cys18/Tyr was expected to disrupt the recently determined disulfide linkage Cys17-Cys18, whereas the mutation Cys20/Ser was expected to disrupt the disulfide linkage Cys19-Cys20. Similar to those N-terminal Cys mutants, these C-terminal Cys mutant preparations contained extra high and low molecular weight proteins in SDS-PAGE (Fig. 4A,D). As confirmed by immunoblot analysis (Fig. 4E), these co-eluted proteins represent either dimerized intact IGFBP-4 or IGFBP-4 proteolytic fragments due to the action of $E$. coli proteases. The Cys20/Ser mutant migrated more slowly than the wild type IGFBP-4 and the two other mutants, although the expected molecular weights of these peptides should be very similar (Fig. 4A,B,C). This shift in apparent molecular mass of Cys20/Ser is likely due to the conformational change caused by this particular mutation, since all of the three mutant peptides 
[A]

6xHis-BP-4

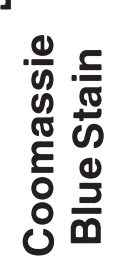

[B]

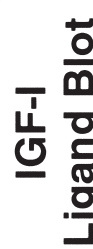

[C]

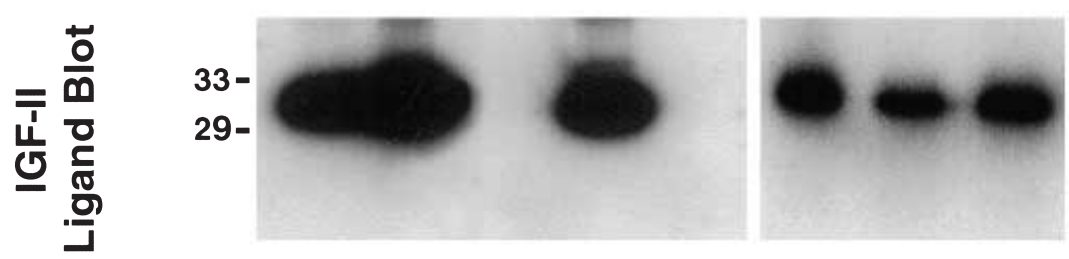

[D]
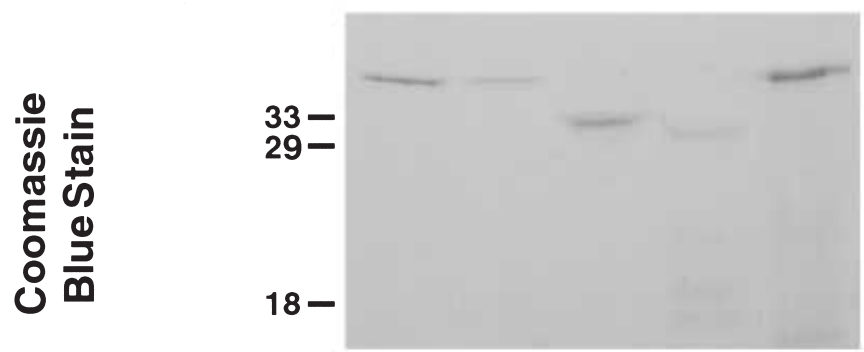

[E]

응
응
들
틀

33-

29-
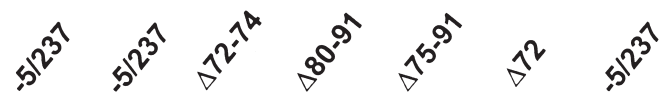

$\widehat{s}^{\hat{\imath}^{\hat{3}}}$
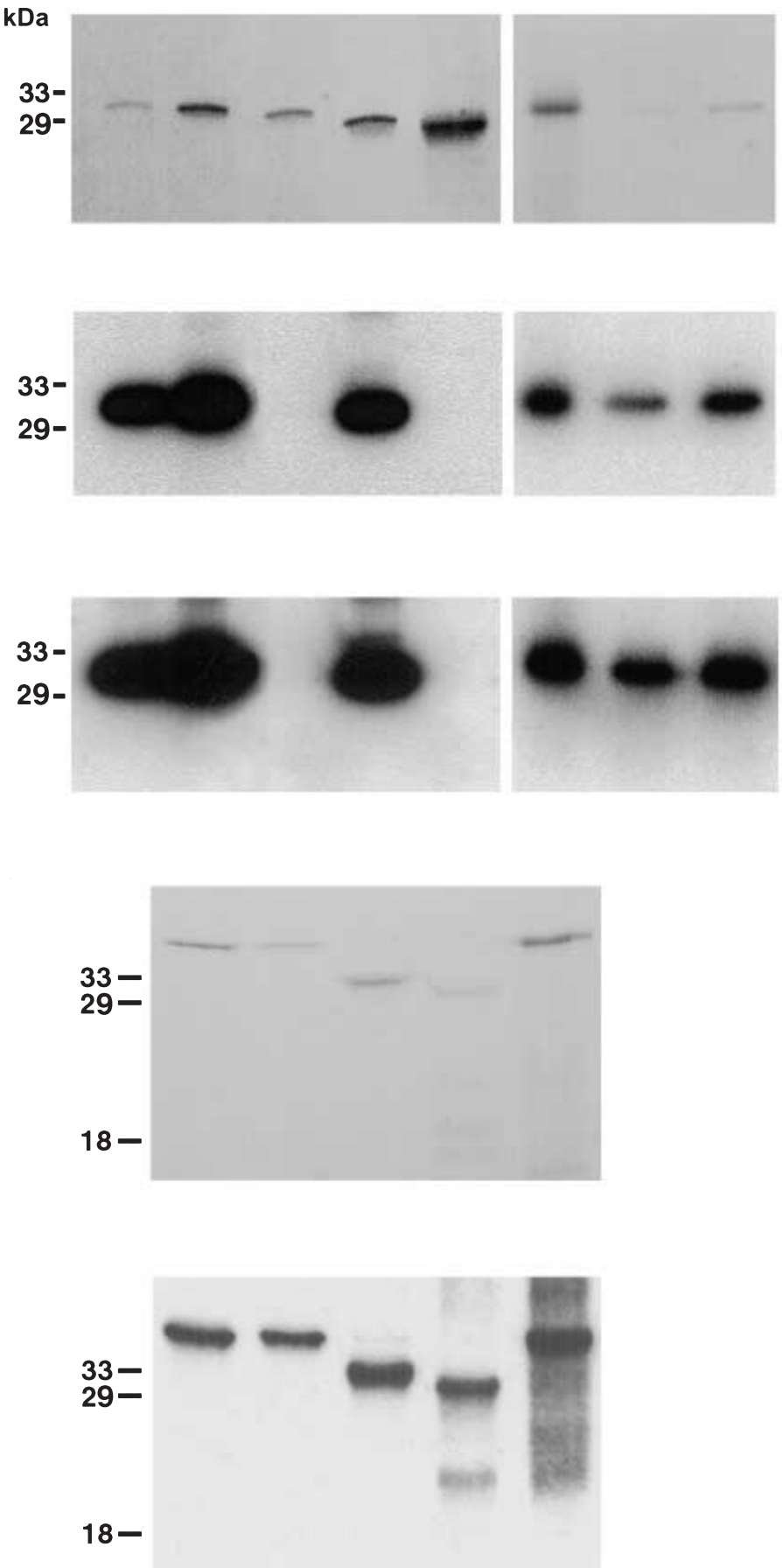

Figure 1 Western ${ }^{125}$ I-IGF ligand blot and immunoblot analyses of the IGFBP-4 peptides with amino acid deletions. In A, B, and C, purified proteins were treated with SDS-PAGE loading buffer without reducing agent. Three doses of the wild type IGFBP-4 (160, 80, and $40 \mathrm{ng}$ ) were included. Half of each sample was separated by SDS-PAGE and stained with Coomassie blue (A). One quarter of each sample was used to perform either IGF-I (B) or IGF-II (C) ligand blot analysis. In D and E, purified peptides were treated with SDS-PAGE sample buffer containing $\beta$-mercaptoethanol. Two thirds of each sample were separated by SDS-PAGE and stained with Coomassie blue (D). The remaining one third of each sample was subjected to immunoblot analysis using polyclonal hIGFBP-4 antibody (E). The IGF binding activity of these IGFBP-4 peptides has been confirmed by multiple experiments. 


\section{N-terminal region Central region C-terminal region Reference}
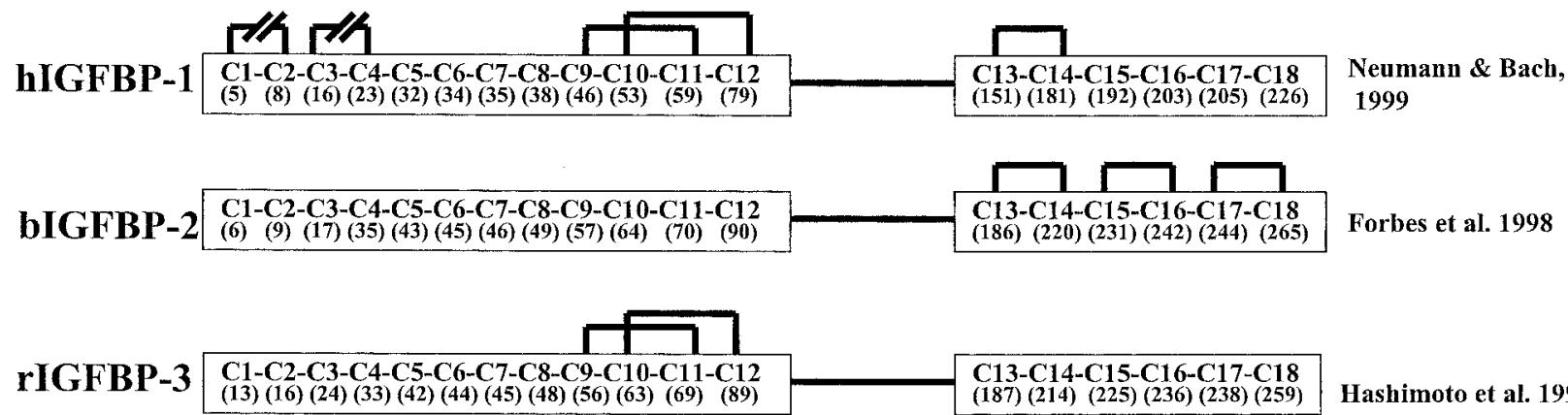

Hashimoto et al. 1997

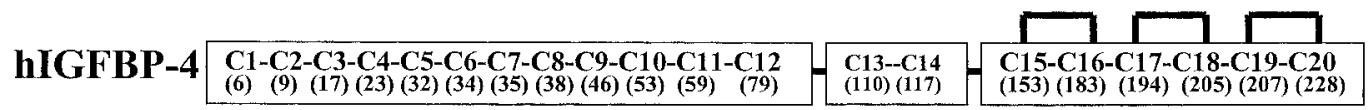

Standker et al. 2000

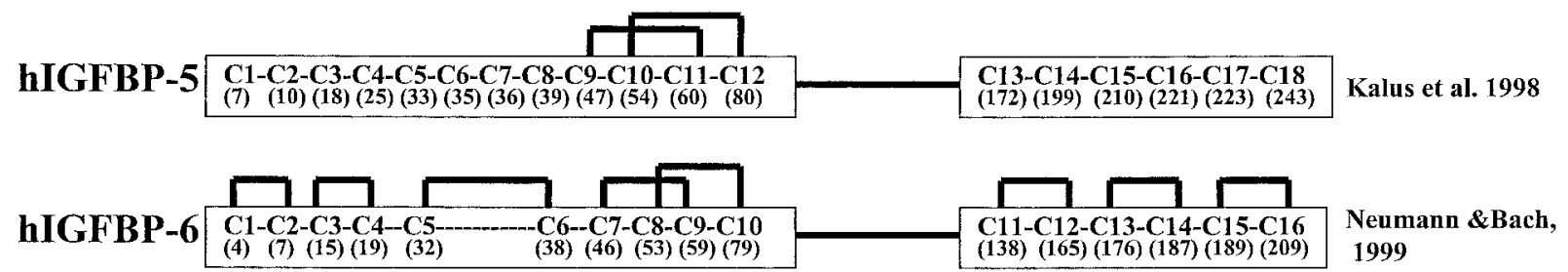

Figure 2 A summary of the previously determined disulfide linkages in IGFBPs. r: rat; b: bovine; h: human. Cys residues were numbered sequentially from the $\mathrm{N}$-terminus. Numbers in parentheses represent actual residue number (the first residue in the mature peptide was designated residue 1). In IGFBP-5, the disulfide bridging was deduced from NMR analysis. In all the other IGFBPs, the disulfide bridging was directly determined by chemical methodologies and/or mass spectrometry. In hIGFBP-1, C1 is not linked to C2 and C3 is not linked to $\mathrm{C} 4$, which is different from the disulfide linkage in IGFBP-6. These previous findings demonstrate that some of the disulfide linkages are conserved whereas others vary among different IGFBPs.

demonstrated a major band, which co-migrated with the wild type IGFBP-4 and reacted with the IGFBP-4 antibody (Fig. 4D,E). As determined by IGF ligand blotting, these C-terminal Cys mutants exhibited approximately a 5 -fold reduction in IGF-II binding activity (Fig. 4B). While these mutations also reduced IGF-I binding activity, the effect of each mutation seemed to vary. The reductions in IGF-I binding caused by the mutation Cys17/Ser and Cys20/Ser were very similar but appeared to be lower than the reduction caused by the Cys18/Tyr mutation (Fig. 4C).

To further confirm the observation that $\mathrm{N}$-terminal Cys residues were more critical than the $\mathrm{C}$-terminal Cys residues in IGF binding, we evaluated IGF-II binding to Cys9/Arg and Cys20/Ser mutants in a solution binding assay (Fig. 5). The estimated IGFBP-4 concentrations at which half maximal IGF-II binding occurred were approximately $0.8 \mathrm{ng} / \mathrm{ml}$ and $4 \mathrm{ng} / \mathrm{ml}$ for the wild-type IGFBP-4 and Cys20/Ser mutant, respectively. This result was consistent with the IGF-II ligand blot analysis, which revealed that the Cys20/Ser mutant exhibited an approximately 5 -fold reduction in IGF-II binding activity compared with the wild-type IGFBP-4. The Cys 9/Arg exhibited a much lower affinity compared with the Cys20/Ser mutant (>15-fold). The IGFBP-4 mutant lacking residues 72-74 did not demonstrate binding affinity with IGF-II as shown previously by the IGF ligand blot analysis (Fig. 1).

\section{Discussion}

One of the important structural characteristics of IGFBPs is that all six IGFBPs contain multiple conserved Cys residues in their $\mathrm{N}$-terminal and $\mathrm{C}$-terminal regions (Fig. 2). These structural features suggest a general role of disulfide linkage in determining the IGF binding activity of IGFBPs. In this study, we have determined, for the first time, the role of several representative Cys residues in IGFBP-4 in IGF binding. Moreover, using full-length IGFBP-4 analogs with targeted amino acid deletions, we have confirmed that the IGF binding domain in IGFBP-4 is located in the distal N-terminal conserved region.

Using sequential deletion analysis, we have previously shown that the IGFBP-4 peptide containing the residues Gly $^{-5}$ to Leu ${ }^{72}$ failed to bind to IGF-I and IGF-II, while 
6xHis-BP-4
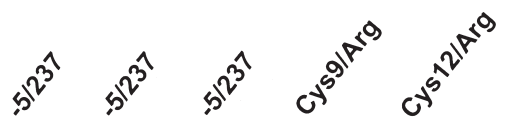

[A]

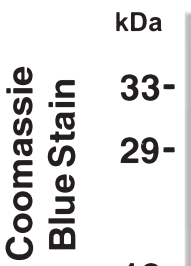

[B]

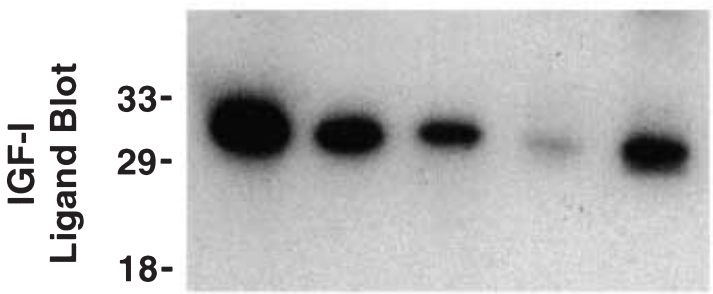

[C]

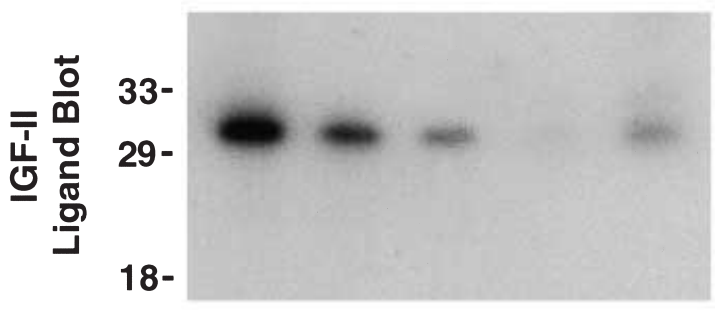

[D]
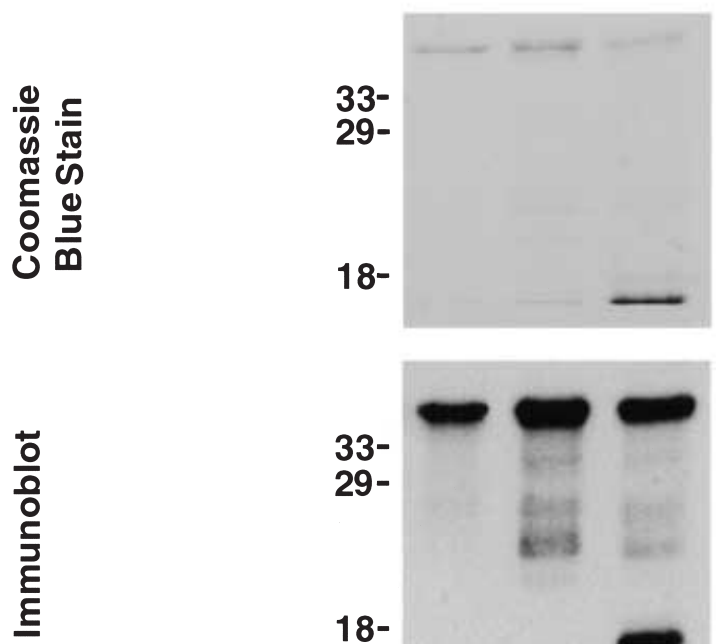

[E]

응

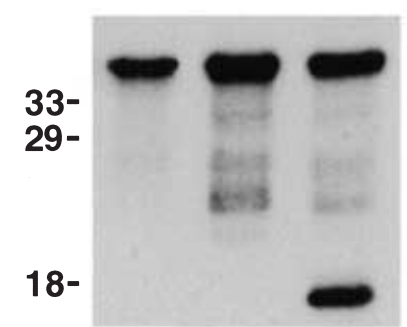

Figure 3 Western ${ }^{125}$ I-IGF ligand blot and immunoblot analyses of the IGFBP-4 peptides with point mutation at N-terminal Cys residues. Sample treatment was identical to that described in Fig. 1. (A) Coomassie blue stain of proteins separated by SDS-PAGE under non-reducing conditions; (B) IGF-I ligand blot; (C) IGF-II ligand blot; (D) Coomassie blue stain of proteins separated by SDS-PAGE under reducing conditions; (E) Western immunoblot of reduced IGFBP-4 peptides. The IGF binding activity of these IGFBP-4 peptides has been confirmed by multiple experiments using IGFBP-4 peptides prepared in different batches. the peptide containing residues $\mathrm{Gly}^{-5}$ to $\mathrm{Ser}^{91}$ retained substantial amount of IGF binding activity (Qin et al. 1998). These data suggest that the IGF binding domain may reside in the region $\mathrm{Leu}^{72}$ to $\mathrm{Ser}^{91}$. This tentative conclusion has now been confirmed in this study by the observation that full-length IGFBP-4 missing residues $\mathrm{Leu}^{72}$ to $\mathrm{Ser}^{91}$ had completely lost IGF binding activity. Since IGFBP-4 peptide lacking residues $\mathrm{Gly}^{75}$ to Ser ${ }^{91}$ failed to bind to IGFs whereas deletion of residues $\mathrm{Met}^{80}-\mathrm{Ser}^{91}$ only had a minimal effect on IGF binding, it is reasoned that residues $\mathrm{Leu}^{72}$ to $\mathrm{Met}^{80}$ may be the most critical residues for IGF binding. Sequence analysis revealed that this motif, $\mathrm{L}^{72}-\mathrm{M}^{73}-\mathrm{H}^{74}-\mathrm{G}^{75}-\mathrm{Q}^{76}-\mathrm{G}^{77}-\mathrm{V}^{78}-$ $\mathrm{C}^{79}-\mathrm{M}^{80}$, is very hydrophobic. In this motif, $\mathrm{His}^{74}$ is the only charged residue. However, substitution of $\mathrm{His}^{74}$ for a hydrophobic residue, Ala, had no effect on either IGF-I or IGF-II binding (Qin et al. 1998). Substitution of $\mathrm{His}^{74}$ for Pro abolished IGF binding possibly because introduction of a Pro residue may have disrupted the secondary structure of this motif by creating a bending in the peptide backbone (Qin et al. 1998). In contrast, deleting the three residues, $\mathrm{Leu}^{72}-\mathrm{Met}^{73}-\mathrm{His}^{74}$, completely abolished IGF-I and IGF-II binding, and deletion of the single residue, $\mathrm{Leu}^{72}$, led to a 2-fold reduction in IGF binding. These data suggest that the residues $\mathrm{Leu}^{72}$ and $\mathrm{Met}^{73}$ in this hydrophobic motif in IGFBP-4 may be important in IGF binding. These findings are consistent with the results from a study on the interaction between IGFBP-5 and IGF-I by nuclear magnetic resonance (NMR), which suggest that the residues $\mathrm{Ly}^{68}, \mathrm{Pro}^{69}, \mathrm{Leu}^{70}, \mathrm{Leu}^{73}$, and $\mathrm{Leu}^{74}\left(\mathrm{Leu}^{74}\right.$ in IGFBP-5 is analogous to $\mathrm{Leu}^{72}$ in IGFBP-4) constitute a hydrophobic patch on the surface of IGFBP-5 and form the IGF binding domain (Kalus et al. 1998). This prediction by NMR is confirmed by the most recent finding that simultaneous mutation of $\mathrm{Lys}^{68}$ to Asn, and the other four residues to Gln in IGFBP-5 essentially abolished the IGF-I binding activity (Imai et al. 2000). Taken together, these new findings strongly suggest that the IGF binding domain in IGFBP-4 as well as in IGFBP-5 may involve a hydrophobic motif located in the distal part of the conserved N-terminal region.

Disulfide bond linkage is important in maintaining the structures required for IGF binding since reduced IGFBPs conferred little IGF binding activity (Qin et al. 1998, Neumann \& Bach 1999). It has previously been shown that several N-terminal Cys residues and a C-terminal Cys residue in IGFBP-1 are critical for IGF binding (Brinkman et al. 1991a,b). To date, the disulfide linkage in the N-terminal domain of IGFBP-4 has not been determined. However, based on the conserved disulfide linkage in other IGFBPs (summarized in Fig. 2), in IGFBP-4, Cys9 is likely to be linked to Cys11, and Cys10 to Cys12. Although mutation of either Cys9 or Cys12 each led to a dramatic reduction of IGF binding activity, disulfide linkage involving Cys9 appeared to be more critical for IGF binding. Since the extent of reduction in IGF-I and 

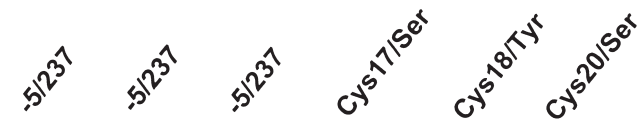

[A]

kDa

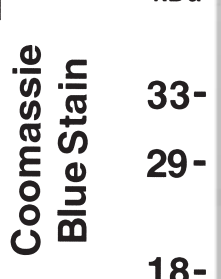

[B]

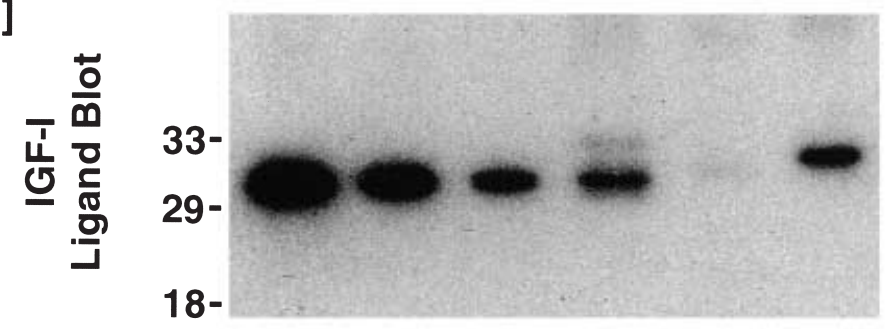

[C]

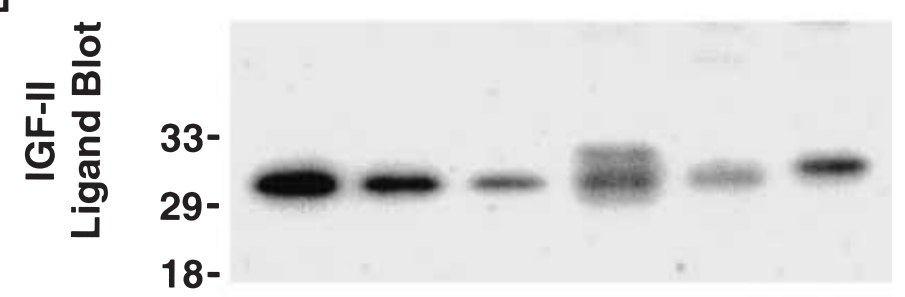

[D]
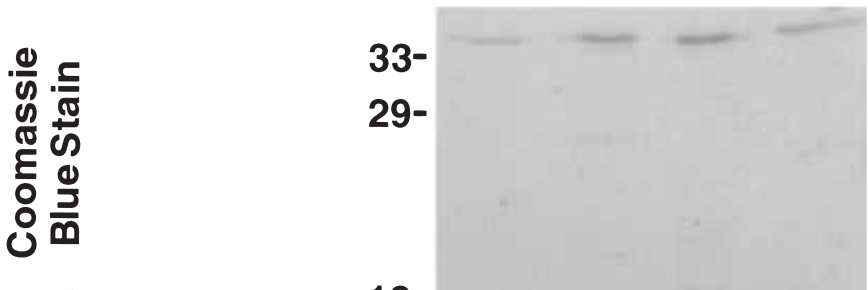

18-

[E] 흥

33-

29-

18-

Figure 4 Western ${ }^{125}$ I-IGF ligand blot and immunoblot analyses of the IGFBP-4 peptides with point mutation at C-terminal Cys residues. Sample treatment was identical to that described in Fig. 1. (A) Coomassie blue stain of proteins separated by SDS-PAGE under

non-reducing conditions; (B) IGF-I ligand blot; (C) IGF-II ligand blot; (D) Coomassie blue stain of proteins separated by SDS-PAGE under reducing conditions; (E) Western immunoblot of reduced IGFBP-4 peptides. The IGF binding activity of these IGFBP-4 peptides has been confirmed by multiple experiments using IGFBP-4 peptides prepared in different batches. 


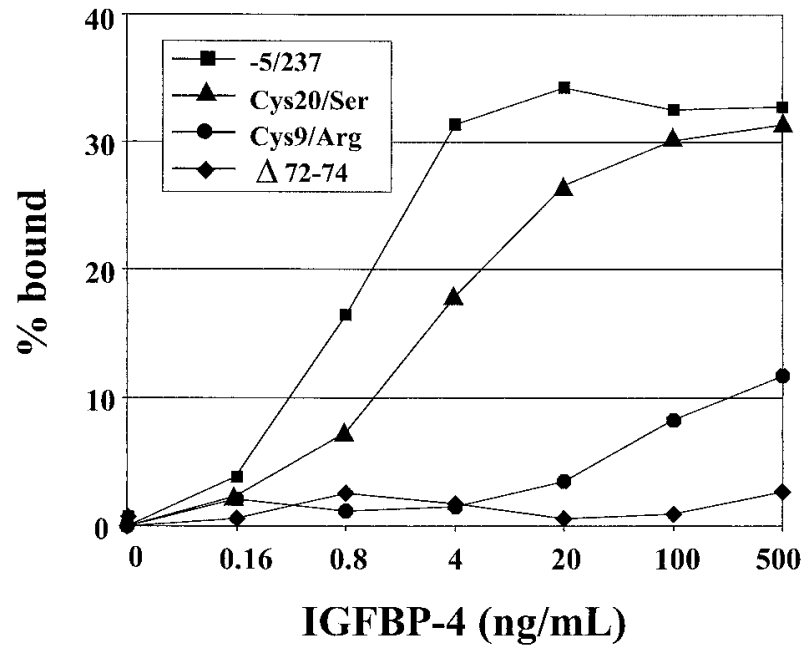

Figure 5 Evaluation of IGF-II binding to representative IGFBP-4 mutants using IGF-II/IGFBP-4 solution binding assay. 50000 c.p.m. of the ${ }^{125}$ I-IGF-II tracer were incubated with 0 to $500 \mathrm{ng} / \mathrm{ml}$ purified IGFBP-4 peptides in $200 \mu$ l binding buffer. The free and bound ${ }^{125}$ I-IGF-II tracer were separated by $25 \%$ polyethylene glycol precipitation as previously described (Mohan et al. 1989). The nonspecific binding determined in the absence of IGFBP-4 peptide was subtracted from the total binding. For clarity, the $x$ axis (IGFBP-4 concentrations) is not to scale.

IGF-II binding is very similar, the disulfide linkages involving these two Cys residues may be equally critical for both IGF-I and IGF-II binding. A more precise interpretation of these data requires a future elucidation of the disulfide linkage profile in the $\mathrm{N}$-terminal domain of IGFBP-4.

During the preparation of this manuscript, the disulfide linkage profile in the conserved C-terminal region of IGFBP-4 has been reported (Standker et al. 2000). Disruption of each of the two of these three C-terminal disulfide linkages had a similar effect on IGF-II binding, although the effect was less dramatic compared with the disruption of the N-terminal disulfide linkages. Since mutation of Cys17 (Cys $\left.{ }^{194}\right)$ or Cys18 $\left(\mathrm{Cys}^{205}\right)$ each should disrupt the same disulfide linkage Cys17-Cys18, we would expect that both mutations should demonstrate a similar effect on IGF binding activity. While mutation of Cys17 or Cys18 led to a similar if not identical extent of reduction in IGF-II binding, mutation of Cys18, unexpectedly, had a greater effect on IGF-I binding than mutation of Cys17. Since Cys18 $\left(\mathrm{Cys}^{205}\right)$ is located in the highly conserved motif, Cys ${ }^{205}-$ Trp-Cys ${ }^{207}-$ Val-Asp ${ }^{209}$, which has been suggested to play a role in enhancing IGF binding activity (Qin et al. 1998), we speculate that mutation of Cys18 may have affected the function of other adjacent residues which may be more critically involved in IGF-I binding than in IGF-II binding. Alternatively, Cys17 may form disulfide linkage with another critical Cys residue after its partner Cys18 is mutated. The resulting mismatch in disulfide linkage may further and preferentially reduce the IGF-I binding activity.

IGFBP-4 is unique in that it contains two extra Cys residues, Cys13 $\left(\mathrm{Cys}^{110}\right.$ ) and Cys14 $\left(\mathrm{Cys}^{117}\right)$, in the central region. Although we did not provide direct evidence for the role of these two Cys residues in IGF binding because of the difficulties of mutating these residues, Cys13 and Cys14 do not seem to be critical based on our previous finding that the IGFBP-4 analog lacking residues Pro ${ }^{94}$ to $\operatorname{Gln}^{119}$ exhibited similar IGF-I or IGF-II binding activity compared with the wild type (Qin et al. 1998, 1999).

In summary, results from this study suggest that the IGF-I and IGF-II binding domain in IGFBP-4 involves a hydrophobic motif located in the distal part of the conserved N-terminal region. The N-terminal Cys residues (Cys9 and Cys12) are more critical than the C-terminal Cys residues (Cys17 and Cys20) in affecting IGF-I and IGF-II binding. Cys18 is more critical in affecting IGF-I than IGF-II binding activity. Based on these new data and our previous findings, we speculate that the structural determinants for both IGF-I and IGF-II binding in hIGFBP-4 are very similar if not identical.

\section{Acknowledgements}

We thank Joe Rung-Aroon for excellent technical support, and the Medical Media Department in the J L Pettis VA Medical Center for the illustrations. The authors also thank Ms. Carol Farrell for secretarial help. This work was supported by grants from the National Institutes of Health (R0-3 AR 45081-01 and R0-1 AR45210 to X Q and R0-1 AR31062 to S M) and the facilities of the J L Pettis VA Medical Center.

\section{References}

Brinkman A, Kortleve DJ, Schuller AG, Zwarthoff EC \& Drop SL 1991 a Site-directed mutagenesis of the N-terminal region of IGF binding protein 1: analysis of IGF binding capability. FEBS Letters $291264-268$.

Brinkman A, Kortleve DJ, Zwarthoff EC \& Drop SL $1991 b$ Mutations in the C-terminal part of insulin-like growth factor (IGF)-binding protein-1 result in dimer formation and loss of IGF binding capacity. Molecular Endocrinology 5 987-994.

Canalis E 1993 Insulin-like growth factors and the local regulation of bone formation. Bone 14 273-276.

Clemmons DR 1997 Insulin-like growth factor binding proteins and their role in controlling IGF actions. Cytokine and Growth Factor Review 8 45-62.

Forbes BE, Turner D, Hodge SJ, McNeil KA, Forsberg G \& Wallace JC 1998 Localization of an insulin-like growth factor (IGF) binding site of bovine IGF binding protein-2 using disulfide mapping and deletion mutation analysis of the C-terminal domain. Journal of Biological Chemistry 273 4647-4652.

Hashimoto R, Ono M, Fujiwara H, Higashihashi N, Yoshida M, Enjoh-Kimura T \& Sakano K 1997 Binding sites and binding 
properties of binary and ternary complexes of insulin-like growth factor-II (IGF-II), IGF-binding protein-3, and acid-labile subunit. Journal of Biological Chemistry 272 27936-27942.

Honda Y, Landale E, Strong DD, Baylink DJ \& Mohan S 1996 Recombinant synthesis of insulin-like growth factor binding protein-4 (IGFBP-4): development, validation and application of a radioimmunoassay for IGFBP-4 in human serum and other biological fluids. Journal of Clinical Endocrinology and Metabolism 81 $1389-1396$.

Imai Y, Moralez A, Andag U, Clarke JB, Busby WH Jr \& Clemmons DR 2000 Substitutions for hydrophobic amino acids in the $\mathrm{N}$-terminal domains of IGFBP-3 and -5 markedly reduce IGF-I binding and alter their biologic actions. Journal of Biological Chemistry $27518188-18194$.

Kalus W, Zweckstetter M, Renner C, Sanchez Y, Georgescu J, Grol M, Demuth D, Schumacher R, Dony C, Lang K \& Holak TA 1998 Structure of the IGF-binding domain of the insulin-like growth factor-binding protein-5 (IGFBP-5): implications for IGF and IGF-I receptor interactions. EMBO Journal 17 6558-6572.

Landale EC, Strong DD, Mohan S \& Baylink DJ 1995 Sequence comparison and predicted structure for the four exon-encoded regions of human insulin-like growth factor binding protein 4 . Growth Factors 12 245-250.

Miyakoshi N, Richman C, Qin X, Baylink DJ \& Mohan S 1999 Effects of recombinant insulin-like growth factor-binding protein-4 on bone formation parameters in mice. Endocrinology 140 $5719-5728$.

Mohan S \& Baylink DJ 1999 IGF system components and their role in bone metabolism. In The IGF System, edn 1, pp 457-496. Eds RG Rosenfeld \& CT Roberts. Totowa, New Jersey: The Humana Press, Inc.

Mohan S, Bautista CM, Wergedal J \& Baylink DJ 1989 Isolation of an inhibitory insulin-like growth factor (IGF) binding protein from bone cell-conditioned medium: a potential local regulator of IGF action. PNAS 86 8338-8342.

Mohan S, Nakao Y, Honda Y, Landale E, Leser U, Dony C, Lang K \& Baylink DJ 1995 Studies on the mechanisms by which insulinlike growth factor (IGF) binding protein-4 (IGFBP-4) and IGFBP-5 modulate IGF actions in bone cells. Journal of Biological Chemistry 270 20424-20431.
Mohseni-Zadeh S \& Binoux M 1997 Insulin-like growth factor (IGF) binding protein-3 interacts with the type 1 IGF receptor, reducing the affinity of the receptor for its ligand: an alternative mechanism in the regulation of IGF action. Endocrinology 138 5645-5648.

Neumann GM \& Bach LA 1999 The N-terminal disulfide linkages of human insulin-like growth factor-binding protein-6 (hIGFBP-6) and hIGFBP-1 are different as determined by mass spectrometry. Journal of Biological Chemistry 274 14587-14594.

Qin X, Strong DD, Baylink DJ \& Mohan S 1998 Structure-function analysis of the human insulin-like growth factor binding protein-4. Journal of Biological Chemistry 273 23509-23516.

Qin X, Byun D, Strong DD, Baylink DJ \& Mohan S 1999 Studies on the role of human insulin-like growth factor-II (IGF-II)-dependent IGF binding protein (hIGFBP)-4 protease in human osteoblasts using protease-resistant IGFBP-4 analogs. Journal of Bone and Mineral Research 14 2079-2088.

Rosen CJ, Donahue LA \& Hunter SJ 1994 Insulin-like growth factors and bone: the osteoporosis connection. Proceedings of the Society for Experimental Biology and Medicine 206 83-102.

Scharla SH, Strong DD, Mohan S, Baylink DJ \& Linkhart TA 1991 1,25-Dihydroxyvitamin D3 differentially regulates the production of insulin-like growth factor-I (IGF-I) and IGF-binding protein-4 in mouse osteoblasts. Endocrinology 129 3139-3146.

Standker L, Braulke T, Mark S, Mostafavi H, Meyer M, Honing S, Gimenez-Gallego G \& Forssmann WG 2000 Partial IGF affinity of circulating $\mathrm{N}$ - and C-terminal fragments of human insulin-like growth factor binding protein-4 (IGFBP-4) and the disulfide bonding pattern of the C-terminal IGFBP-4 domain. Biochemistry 39 5082-5088.

Valentinis B, Bhala A, DeAngelis T, Baserga R \& Cohen P 1995 The human insulin-like growth factor (IGF) binding protein-3 inhibits the growth of fibroblasts with a targeted disruption of the IGF-I receptor gene. Molecular Endocrinology 9 361-367.

Received in final form 21 November 2000 Accepted 29 November 2000 